\title{
Challenges in monitoring and managing engineered slopes in a changing climate
}

\author{
Paul N Hughes ${ }^{1, a}$, Rosalind Hen-Jones ${ }^{2}$, Ross A Stirling ${ }^{2}$, Stephanie Glendinnning ${ }^{2}$, David A Gunn ${ }^{3}$, Jonathon E \\ Chambers $^{3}$, Tom A Dijkstra ${ }^{3}$, Joel Smethurst ${ }^{4}$, and Kristine Flesjo ${ }^{5}$ \\ ${ }^{1}$ School of Engineering and Computing Sciences, Durham University, Durham, UK. \\ ${ }^{2}$ School of Civil Engineering and Geosciences, Newcastle University, Newcastle, UK \\ ${ }^{3}$ British Geological Survey, Keyworth, UK \\ ${ }^{4}$ School of Engineering and the Environment, University of Southampton, UK \\ ${ }^{5}$ Norwegian Public Roads Administration, Os/o, Norway
}

\begin{abstract}
Geotechnical asset owners need to know which parts of their asset network are vulnerable to climate change induced failure in order to optimise future investment. Protecting these vulnerable slopes requires monitoring systems capable of identifying and alerting to asset operators changes in the internal conditions that precede failure. Current monitoring systems are heavily reliant on point sensors which can be difficult to interpret across slope scale. This paper presents challenges to producing such a system and research being carried out to address some of these using electrical resistance tomography (ERT). Experimental results show that whilst it is possible to measure soil water content indirectly via resistivity the relationship between resistivity and water content will change over time for a given slope. If geotechnical parameters such as pore water pressure are to be estimated using this method then ERT systems will require integrating with more conventional geotechnical instrumentation to ensure correct representative information is provided. The paper also presents examples of how such data can be processed and communicated to asset owners for the purposes of asset management.
\end{abstract}

\section{Introduction}

There is an urgent need to better understand the medium to long-term implications of climate change on engineered slopes to make pro-active interventions more cost-effective and to better understand the scale of financial and societal consequences of future failures requiring re-active mitigation, repair or replacement. Many components of our transport infrastructure system that supports our population and economy have little or no resilience, so even minor changes in environmental conditions can cause compromises of serviceability or even lead to complete failure resulting in potentially severe consequences for asset owners and users. Engineered slopes (cuttings, embankments, flood defences) are a critical component of this infrastructure and where slopes exhibit excess deformation this causes delays and economic loss to European industry and the general public, while at the same time posing a significant safety hazard. Climate change projections across Europe are varied and there will be important regional differences in how this is manifested and how this will impact on the performance of engineered slopes for transport infrastructure. One of the important regional examples that requires further investigation includes an increased likelihood of summer drought leading to drying/cracking of soil which will in turn lead to

\footnotetext{
a Corresponding author: paul.hughes2@durham.ac.uk
}

increased macro permeability and hence more rapid ingress of water during extreme precipitation) $[1,2]$.

\subsection{Climate change context}

Projections of future climate change suggest a move toward drier summers and wetter winters in northern Europe and a reduction in annual rainfall in southern Europe [3], with associated changes in ground condition and hence implications for slope stability. It is well understood that increasing ground water decreases soil strength and can lead to swelling of some clay soils [4] and that conversely drying increases soil strength but causes shrinkage and desiccation cracking [5]. These moisture-driven changes have the potential to increase the incidence of failure across a range of earth structures $[6,2]$ affecting road and rail networks. Whilst the magnitude of these impacts is not yet fully understood, engineers and asset managers require reliable and cost effective systems to monitor the condition of these assets and direct maintenance activities at the most vulnerable parts of the network.

Asset owners need to know which parts of their asset network are vulnerable to climate change induced failure in order to optimise future investment. We require models to help us identify vulnerable elements of infrastructure networks, based on prediction of failures, 
to be able to provide sound advice on maintenance, remediation and adaptation measures. As an example, approximately one third of the total asset value of the UK transport network is derived from infrastructure slopes [7]. Maintaining this network is costly; it is estimated that in the UK, Network Rail spent $£ 70$ million in 2007/2008 on preventative works to stabilize earthworks [8,9].

COST Action TU1202 is a coalition of researchers addressing the challenges of engineered slope infrastructure resilience and adaptation to climate change in Europe. The research network has four focus areas, slope data and monitoring; soil/vegetation/climate interactions; slope numerical modelling and risk assessment. Overcoming the challenges of monitoring and managing slope stability risk in a changing climate requires integration of these approaches. This paper presents some of the work conducted by COST TU1202 towards this integration.

\subsection{Monitoring}

At-risk engineered slopes are routinely monitored using geotechnical instrumentation that focusses on the measurement of ground water condition and deformation. These instruments are usually augmented by meteorological monitoring in the form of weather stations or simple rain gauges. Rainfall amount is the most widely used parameter for identifying a trigger value for early warning systems for landslides. However, it is recognized that there is a series of processes separating the parameter being measured (rainfall) and the pore water pressure change that will cause the slope to fail and that the measurement of pore water pressure is the most reliable predictor of failure in a slope [10] and therefore the more useful parameter to use when planning preventative maintenance in engineered slopes. Deformation monitoring informs when a slope is moving and provides valuable information about rates and magnitudes of movement which is also useful in planning remediation works.

Traditionally, ground water and deformation monitoring in engineering applications has been performed through the use of piezometers, tensiometers, inclinometers and extensometers $[10,11,12]$ which have increased in sophistication and reduced in price over time. Improvements in digital communications and power management in these instruments have enabled a much greater degree of autonomous operation reducing the demands for manual reading of instruments. However, direct monitoring in this way remains expensive (from both an equipment and human resource perspective) and is only able to provide single point values which may be unreliable and require much effort to resolve a spatiallyintegrated cross-sectional model.

Monitoring of ground movement over larger areas can be accomplished using aerial reconnaissance and LIDAR and is done regularly by asset owners such as Network Rail in the UK [13] but these surveys provide topographical information only [14] and therefore are not currently capable of capturing potentially rapid changes in subsurface conditions preceding slope failure.
Geophysical monitoring using techniques such as Electrical Resistance Tomography (ERT) has the potential to bridge this gap in scale and has been used by numerous researchers to monitor larger areas than traditional instrumentation $[15,16]$.

Protection of at risk slope assets requires risk-based early intervention. However, such interventions require monitoring systems capable of identifying and alerting to asset operators the changes in the internal conditions that precede failure, in real time. The creation of such a system requires:

1. Instrumentation that can sample a sufficiently large area/volume to be representative of at-risk slopes.

2. Automated logging systems that can convert proxy measurements (such as geophysical data) into geotechnical engineering parameters.

3. Communications and data management systems that can collect and integrate multiple data types from multiple sources coupled to robust modelling capable of processing and analyzing environmental and slope data in near real time.

4. Decision support interfaces that can communicate the analysis to asset operators in a timely fashion.

Achieving this capability presents a number of technical and research challenges. Research presented in this paper focusses on one potential method to overcome challenges 1 and 2. Progress towards overcoming challenges 3 and 4 are presented in the discussion.

\section{Electrical Resistivity Tomography}

Electrical Resistivity Tomography (ERT) is a ground imaging technique that is being increasingly applied to the characterisation and monitoring of the subsurface [17]. Resistivity is particularly sensitive to changes in pore fluid resistivity and saturation as the principal mode of current flow in the subsurface is through electrolytic conduction in the pore fluid; consequently, ERT is widely used in hydro-geophysical investigations [18]. ERT can also be used to distinguish between lithologies of contrasting resistivity, where resistivity can vary due to differing porosities [19] or due to the presence of clay minerals [20,21]. A key advantage of using ERT techniques is the capability to monitor large volumes of the ground using either 2D or 3D arrays (Figure 1).

Although there are an increasing number of studies using three-dimensional ERT (using electrode arrays) as a means of characterising and monitoring unstable slopes $[15,22,23,24]$, relevant geophysical - geotechnical relationships require further validation. As elevated water contents and a corresponding reduction of soil suction are associated with shear failure, their interaction with soil resistivity is key to the development of a slope stability assessment system.

Many studies have investigated the relationship between electrical resistivity and water content for clays 
both in the laboratory $[25,26,27]$ and in the field $[28,29]$. However, in order to fully resolve these relationships, it is necessary to investigate how they are affected by repeated seasonal cycles, which have been shown to progressively weaken clay fills [30]. This process is likely to be exacerbated by the increasingly frequent and extreme weather events suggested by climate change projections.

Studies on partially-saturated rocks [31] and sands $[32,33]$ observed hysteresis in the electrical response to varying degrees of saturation between imbibition (wetting) and drainage; a study by Muñoz-Castelblanco et al, [34] on a natural unsaturated loess found soil resistivity to be independent of whether a drying or a wetting path was followed. However, there is little research into the effects of repeated seasonal cycles on the resistivity response of volume-sensitive clay soils. Hysteresis in near-surface soils is well-established in the soil water retention curve $[35,36,37]$ whereby at a given water content a decrease in soil suction is observed between the drying and the wetting paths, due to entrapped air.

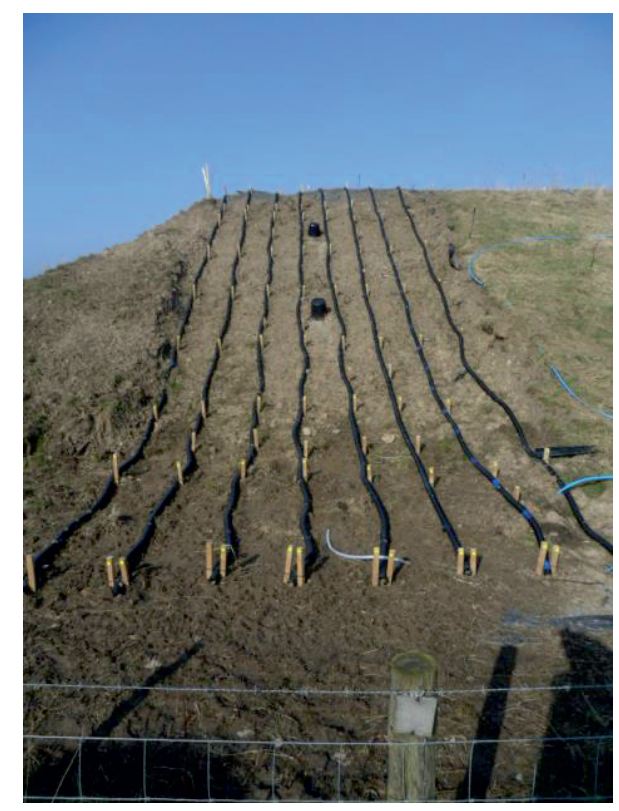

Figure 1. 3D Resistivity array at Bionics test site.

If ERT is to fulfil its potential in geotechnical monitoring then it is necessary to understand how soil suction and resistivity interact when subjected to seasonally varying water content, in order to be able to interpret geophysical information gathered from electrical resistivity tomography arrays. To this end, an experimental programme integrating field monitoring and multi-scale laboratory tests has been undertaken on a Glacial Till clay material obtained from a full-scale test embankment in Northumberland, United Kingdom, which forms part of the BIONICS field research project $[2,6]$. The experiments have been designed to establish the relationships between soil water content, resistivity and pore water pressure, with a particular focus on whether these relationships remain constant over time.

\subsection{Resistivity as a pore water pressure proxy}

BIONICS clay soil was tested to establish its soil water retention (SWR) and electrical resistivity properties. In the SWR phase of the experiment thirteen $38 \mathrm{~mm}$ diameter $\times 8 \mathrm{~mm}$ length discs were formed by placing $18.5 \mathrm{~g}$ of clay (at $22 \%$ water content) into a compaction cell at a strain rate of $0.33 \mathrm{~mm} / \mathrm{min}$ to achieve a target dry density of approximately $1.6 \mathrm{Mg} / \mathrm{m}^{3}$ (chosen to represent in-situ conditions at the BIONICS test site). The specimens were then subjected to moisture cycling: drying was achieved by allowing the specimens to air-dry in a temperature-controlled environment $\left(20^{\circ} \mathrm{C}\right)$, until their masses corresponded to target water contents at regular intervals between $22 \%$ and the residual; wetting was achieved by spraying specimens using a handpowered water mister. Eight specimens were used for stage 1a (drying), whilst five specimens were reserved for stage $1 \mathrm{~b}$ (wetting). Following moisture cycling, the specimens were wrapped in plastic film and allowed to homogenise for a further 24 hours. The specimens were then put in a WP4 dew-point potentiometer [38] and their pore pressures recorded before being oven-dried to confirm their water content.

In the resistivity phase of the experiment seventy five cylindrical soil specimens $(38 \mathrm{~mm}$ diameter by $76 \mathrm{~mm}$ length) were prepared using a steel mould filled by tamping of four approximately equal layers to a target density of $1.6 \mathrm{mg} / \mathrm{m} 3$ to represent field conditions. The drying component of moisture cycling was achieved by the same method as used for the SWR samples wetting was achieved by placing specimens in a "humidity chamber" (an insulated box with two $90 \mathrm{ml} /$ hour mist generators submerged in deionised water, with a grate above to hold the specimens (Figure 2)). The reason for the difference in wetting procedure with respect to SWRC specimens is the larger volume of these specimens such that they required a more intense and prolonged wetting environment to achieve the same moisture content. Resistivity samples were subjected two complete cycles of drying and re-wetting. Specimens were then tested for resistivity using the two-point method, in accordance with BS 1377-3: 1990 [39]. To improve contact resistance at the soil-electrode interface, the disc electrodes were coated with a layer of Nyogel conductive grease.

In addition to the above tests the effects of desiccation cracking on soil resistivity were also investigated using the two-point method. In order to stimulate desiccation cracks, fourteen specimens were prepared with in-built planes of weakness which would be more vulnerable to cracking as shrinkage occurred during drying. This was achieved by tamping after the addition of each of the four layers, creating a deliberately smooth surface, orthogonal to the direction of current flow. For this series of tests, a single stage of drying only was performed. 


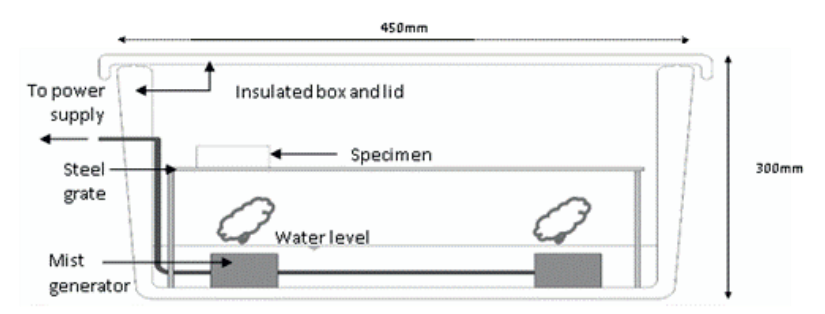

Figure 2. Humidity Chamber

\subsection{Pore water pressure / resistivity results}

The WP4 dewpoint potentiometer was used to measure suction values, which were subsequently fitted using the van Genuchten [40] expression. Both continuous drying and wetting paths were fitted using the van Genuchten fitting parameters $n=1.54, \alpha=0.0097 \mathrm{~m}^{-1}$ and $n=1.29$, $\alpha=0.1001 \mathrm{~m}^{-1}$ respectively (where $m=1-1 / n$ ) (Figure 3 ). The drying curve rapidly de-saturates from $\theta s=0.36$ at an approximate air entry value of $600 \mathrm{kPa}$. The drying path is shown to fit well, though the wetting path suffers from a reduced number of data points. However, in the measured suction range, the fitted curve is shown to pass through the majority of points. Traditionally, for the wetting path, re-saturated water content is observed to be reduced from the initial content due to the entrapment of air. The presented curve displays an inferred, elevated resaturated water content on the wetting path considered as a product of increased porosity as a direct result of the formation of micro-cracking and permanent fabric modification, as described in later in the paper. This trend is predicted due to the extreme drying (desiccation) that the specimens had undergone during the latter stages of drying prior to re-wetting. However, limitations in the dewpoint potentiometer technique do not allow behaviour at very low suctions to be accurately investigated.

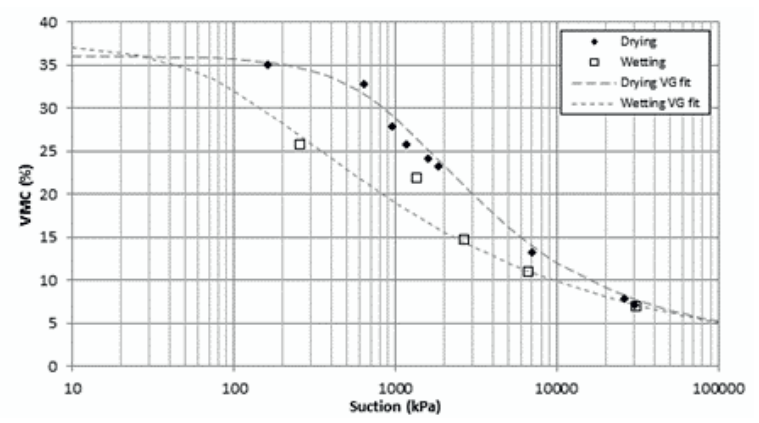

Figure 3. Soil water retention curve

Figure 4 shows the water content - resistivity data are separated into four individual stages (stage 1 drying and wetting; stage 2 re-drying and re-wetting). Little hysteresis can be observed between the stages, demonstrating that the relationship is not significantly affected by whether a drying or a wetting path is followed. However, if the data are divided broadly into stages 1 and 2 (each comprising a full dry-wet cycle), then a hysteretic inverse power relationship is evident.
There is a shift of the resistivity - water content path centred at approximately $22 \% \mathrm{VWC}$, such that below this point, stage 2 specimens have elevated values of resistivity with respect to stage 1 , with the opposite being true beyond this point, as is illustrated by two grey arrows. As before, resistivity error bars of $+/-14 \%$ show that this shift is likely to be significant.

Figure 5 shows a drying curve comparing intact specimens and those with built-in horizontal fracture planes (orthogonal to the current flow). As can be seen in the figure, fractured specimens exhibited higher values of resistivity for a given water content, consistent with an increased porosity as air within the voids acts to impede current flow. Error bars of $+/-14 \%$ shown on the figure demonstrate that this shift values is significant.

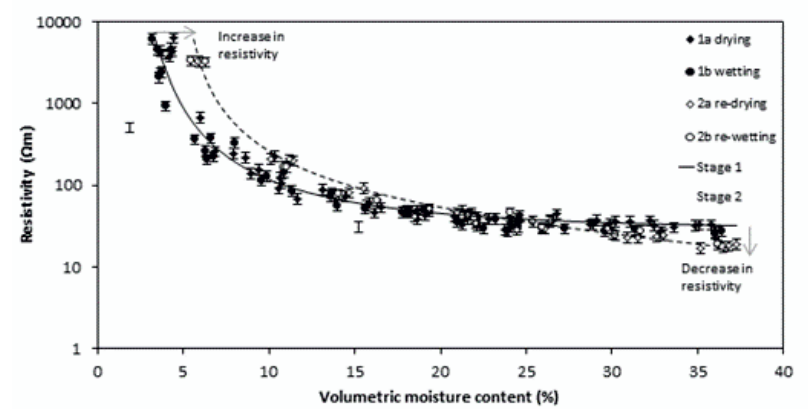

Figure 4. Water content - resistivity relationship separated by seasonal stage

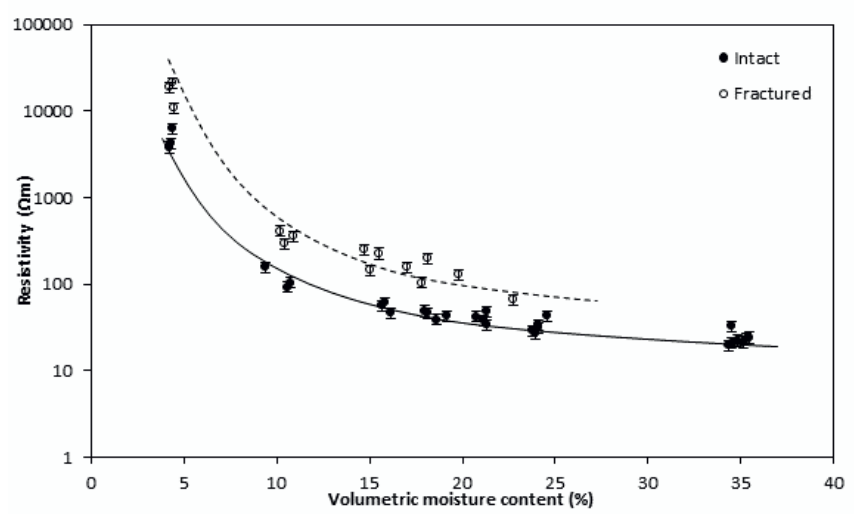

Figure 5. Comparison of water content - resistivity relationship for fractured and intact specimens

\subsection{Implications of results on geophysical/geotechnical monitoring}

Because of its volume-sensitivity, desiccation cracking is associated with clay subjected to dry-wet cycles. In Figure 5, the water content - resistivity relationship for deliberately-fractured specimens is presented alongside that for intact specimens, showing elevated values of resistivity resulting from cracking, resulting from the insulating nature of air acting to impede current flow. Therefore, it could be considered that for clay subjected to such extremes, there would be an increase in resistivity at a given water content with ongoing seasonal cycling, as fractures develop. 
In un-fractured samples exposed to wetting and drying cycles (figure 4) whilst no hysteresis of the resistivity water content relationship can be observed between the wetting and drying paths within one cycle. However, it can be seen that there is a shift between cycle 1 and cycle 2 . Below $22 \%$ VWC specimens subjected to more than one dry-wet cycle have increased values of resistivity with respect to those subjected to less than one. This can be attributed to the development of desiccation cracks. The opposite is true at water contents above $22 \%$, a possible explanation for this reversal between the two phases observed at higher water contents is the dissolution of clay ions in the pore water, such that they become further mobilised with ongoing dry-wet cycling, with existing cracks acting as a high conductivity conduit upon filling with water.

The implications of these results are that if resistivity is to be used as a proxy for water content in geotechnical monitoring a static relationship should not be assumed. It should be anticipated that the relationship between resistivity and water content will change over time in response to environmentally driven structural changes within the soil. It may be necessary to co-locate TDR based point sensors within ERT arrays so that the relationship can be updated over time with new calibration curves applied to the monitoring system automatically in order that representative water contents can be reported in near real time.

Whilst water content is useful in predicting slope behaviour accurate prediction requires knowledge of the pore water distribution within the slope. If the water content distribution is known then it may be possible to estimate pwp using an appropriate soil water retention curve. However, given the hysteretic nature of soil water retention behaviour and the non-uniform periods of wetting and drying that can be expected to occur in the field it is likely that values obtained in this way are only a rough estimate of pwp.

\section{Further challenges}

Geophysical techniques such as ERT provide a potential solution to challenges 1 and 2 listed in section 1.2. The other challenges listed are also being addressed by researchers, stakeholders and instrument manufactures. There are increasingly sophisticated commercial systems that collect and store data, process it into engineering units, and post it onto secure web portals where it can be viewed. Alarms can be set to alert key personnel if certain pre-set trigger levels are exceeded. Standard data formats such as AGS-M, which enable easier sharing of information, are becoming common [41]. These are likely to become more important as assets are monitored over longer periods, giving flexibility in updating hardware and software and interoperability between proprietary systems. Collection and monitoring of more information is part of a technological trend towards 'big data', which is becoming increasingly important across wide areas of the European economy. Data on engineered slopes may be generated during design, construction and operational phases, i.e. the whole life cycle of the asset; geotechnical monitoring information may be part of this data-set. Many large highway and railway infrastructure owners increasingly store information on their assets within large databases, many of which are linked to geographical information systems (GIS). These form a digital representation of the physical and functional characteristics of an asset, and act as a resource for sharing and visualising information and knowledge (e.g. HAGDMS the Highways Agency (now Highways England) Geotechnical data Management System.).

Semi-empirical systems and process-response models continue to be developed [1]. Major transport infrastructure asset managers have progressed investigations into geotechnical risk through the use of morphological and geotechnical characteristics and a variety of research consortia collaborate with asset managers to progress the science underpinning management, maintenance and intervention strategies [1, $2,8,9,14,41]$. Coupling system with near-future weather data (e.g. impending storms) will enable assessing the probability of disruptive slope failure and much can be learned in this context from the flood forecasting community. Prioritisation of sections most at risk will also provide clarity where local monitoring data will be most beneficial and cost-effective. Increasingly large datasets (e.g. Network Rails complete detailed LiDAR coverage of the UK network) creates its own problems in terms of storage, management and processing of large amounts of data, particularly where increasingly sophisticated models require multiple iterations and calculation intensive operations. However, this should not be seen as an impediment as increasing computing power, particularly from cloud-based parallel processing, will make complex operations much more achievable in the future. Traditional monitoring approaches produce periodic reports, which might be attached to an asset within the GIS system. The capability of current systems to hold large data sets is less certain, and may become challenging as the number of sensors and frequency of data logging increases. However, GIS systems that distribute on a fine spatial scale risk information, often in real time (for example, linked to antecedent and forecast rainfall), are becoming more commonplace, and it is plausible that in the future this could include effective integration of regularly updated, multiple datasets (including near real-time weather and asset monitoring data). A good example of this is the Norwegian national system XGEO where data inputs and derived information are available on a $1 \mathrm{~km}$ grid at a national scale (Figure 6). 


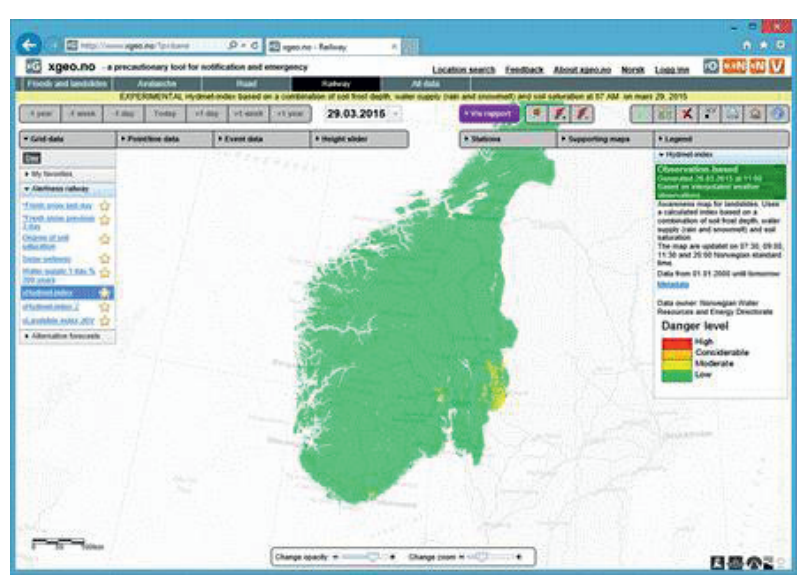

Figure 6. Norwegian XGEO system, an example of (example shows colour coded landslide hazard).

\section{Conclusions}

There remain significant challenges to be overcome in the development of integrated stability monitoring systems that can provide real time warning of impending failure over large lengths of engineered slope. The aging nature of our infrastructure coupled with the anticipated effects of climate change makes the need for these systems more pressing. However, many of the technologies and techniques required to produce such a system are either in development or are currently deployed. Geophysical monitoring has the potential to provide data from large slope volumes which can be integrated with direct point measurement of water content, pore water pressure and weather data to provide live calibration. Mobile communications and database systems already exist that are capable of transmitting and processing slope data and metrological information which can be presented as slope failure risk via user friendly web pages.

More work is still required to characterise slope material properties and establish geophysical/geotechnical property interrelationships. This characterisation will require an understanding of the way soil geotechnical properties change and deteriorate due to environmental drivers such as wetting and drying, freezing and thawing and vegetation growth. Systems will also need to be coupled with robust numerical modelling capable of taking these deterioration factors into account. Achieving this will require collaboration between researchers and developer across a range of fields of expertise including geotechnics, hydrology, transport planning, electronics, communications software development, climate change and with asset owners to ensure systems met the demands of industry.

\section{Acknowledgements}

The authors would like to acknowledge funding provided by EU-COST Action TU1202, the Natural Environment Research Council (GA/12S/007), the BGS British University Funding Initiative (S223), iSMART (EP/K027050/1), and Assessing the Underworld
(EP/K021699/1). Tom Dijkstra, Jon Chambers and David Gunn publish with the permission of the Executive Director of the British Geological Survey.

\section{References}

1. Dijkstra, T. \& Dixon, N. 2010. QJEG\&H, 43, 4, 371-385.

2. Glendinning S, Hughes PN, Helm P, Chambers J, Mendes J, Gunn D, Wilkinson P, Uhlemann S (2014). Acta Geotech 9(5):799

3. EEA 2015. European Environment Agency, Denmark.

4. Driscoll R (1983). Géotechnique 33:93-105

5. Stirling RA. 2014. Multiphase modelling of desiccation cracking in compacted soils. $\mathrm{PhD}$ Thesis, Newcastle University, UK. Hughes PN, Glendinning S, Mendes J, Parkin G, Toll DG, Gallipoli D, Miller P (2009). Proc Inst Civil Eng Eng Sustain 162(2):67-79

6. Perry J, Pedley M, Reid M (2001). CIRIA, Report C550.

7. Rail Accident and Investigations Branch (RAIB) (2008) Network Rail's management of existing earthworks. Department for Transport, London

8. Dijkstra T, Dixon N, Crosby C, Frost M, Gunn D, Fleming P, Wilks J (2014) Proc Inst Civil EngTrans 167(5):269-280.

9. Toll DG, Lourenço SDN, Mendes J, Gallipoli D, Evans FD, Augarde CE, Cui YJ, Tang AM, Rojas JC, Pagano L, Mancuso C, Zingariello C, Tarantino A (2011) QJEG\&H 44(1):23-33

10. Dunnicliff J (1988) Geotechnical Instrumentation for Measuring Field Performance. J Wiley\&Sons, New York

11. Cui YJ, Tang AM, Mantho A, De Laure E (2008) Geotech Testing Journal 31(1):95-100

12. Birch G, Anderson I (2011). Ground Engineering, May 2011

13. Jaboyedoff M, Demers D, Locat J, Locat A, Locat P, Oppikofer T, Robitaille D, Turme D (2009). Can Geotech J 46(12):1379-1390

14. Chambers JE, Wilkinson PB, Kuras O, Ford JR, Gunn DA, Meldrum PI, Pennington CVL, Weller AL, Hobbs PRN, Ogilvy RD (2011). Geomorphology 125:472-484

15. Springman SM, Askarinejad A, Casini F, Friedel S, Kienzler P, Teysseire P, Thielen A (2012). Acta Slovenica Geotechnica 1:5-29

16. Loke MH, Chambers JE, Rucker DF, Kuras O, Wilkinson PB (2013). J Appl Geophys 95:135-156

17. Binley A, Hubbard SS, Huisman JA, Revil A, Robinson DA, Singha K, Slater LD (2015). Water Resour Res 51

18. Archie GE (1942). Transactions of the AIME 146

19. Shevnin V, Mousatov A, Ryjov A, DelgadoRodriquez O (2007). Geophys Prospect 55

20. Russell EJF, Barker RD (2010). Near Surf Geophys

21. Friedel S, Thielen A, Springman SM (2006). J Appl Geophys 60(2) 
22. Merritt AJ, Chambers JE, Murphy W, Wilkinson PB, West LJ, Gunn DA, Meldrum PI, Kirkham M, Dixon N (2014). Landslides 11:537-550

23. Perrone A, Lapenna V, Piscitelli S (2014). Earth-Sci Rev.

24. McCarter WJ (1984). Géotechnique 34(2):263-267

25. Fukue M, Minatoa T, Horibe H, Taya N (1999). Eng Geol 54:43-53

26. Kibria G, Hossain M (2012). J Geotech Geoenviron 138(12):1520-1529

27. Michot D, Benderitter Y, Dorigny A, Nicoullaud B, King D, Tabbagh A (2003). Water Resour Res 39(5):1138

28. Chrétien M, Lataste JF, Fabre R, Denis A (2014). Eng Geol 169: 112-123

29. Loveridge FA, Spink TW, O’Brien AS, Briggs KM, Butcher D (2010). QJEH\&H 43(4):461-472

30. Roberts JJ, Lin W (1997). Water Res Res 33(4):577-587.

31. Knight R (1991). Geophysics 56:2139-2147

32. Kavian M, Slob EC, Mulder WA (2011). J Geophys Res 116: B08214

33. Muñoz-Castelblanco J, Pereira J, Delage P, Cui YJ (2012). ASTM Geotechnical Testing Journal 35(1):11-17

34. Fredlund DG, Xing A (1994). Can Geotech J 31(4):521-532

35. Šimůnek J, Kodešová R, Gribb M, Van Genuchten MT (1999). Water Resour Res 35(5):1329-1345

36. Fredlund, DG, Sheng D, Zhao J (2011). Can Geotech J 48:186-198

37. Decagon Devices (2014) WP4C Dewpoint Potentiometer, operator's manual. Decagon Devices Inc.

38. British Standards Institution (1990) BS 1377-2:, BSI.

39. Van Genuchten MT (1980). Soil Sci Soc Am J 44(5):892-898

40. Richards, D.J., Chandler, R.J. and Lock, A.C. (2003). Proc Inst of Civil Engineers: Geotechnical Engineering, 156, (1), 47-55.

41. Sadler, J., Griffin, D., Gilchrist, A., Austin, J., Kit, O., and Heavisides, J. (2015). GeoSRM - An Online Geospatial Safety Risk Model. 